\title{
CARACTERES DEFINIDORES DE UN SECTOR DEL ORDENAMIENTO JURIDICO
}

\author{
Manuel María Zorrilla Ruiz \\ Catedrático de la Universidad de Deusto \\ Profesor Visitante de la Universidad de Burdeos I (Francia) \\ y de la Universidad de Łodz (Polonia)
}

\section{Consideración previa}

Los compartimentos en que se divide el ordenamiento jurídico se señalan por unos caracteres que, más o menos afortunadamente, contribuyen a individualizarlos. Si su presentación es, por hipótesis, una tarea inacabada, no resulta menos enojosa la que, una vez obtenidos, consiste en ensayar su aplicación a cada uno de dichos sectores. Queda de manifiesto lo incompleto y modesto de una tentativa siempre necesitada de reflexión crítica y esfuerzo de renovación.

\section{Impregnación política del Derecho}

Todo sector del ordenamiento jurídico constituye la expresión normativa de una actitud política - más o menos difusa y teñida de connotaciones ideológicas - que, lejos de mostrarse ajena a la producción de las normas de Derecho objetivo, se propone influir en tal orden de cosas. Las dos corrientes que, hasta no hace poco, han marcado la división de preferencias del medio cultural más cercano abundaban en esta consideración.

Cada porción de un ordenamiento jurídico del modelo de Estado social y democrático de Derecho se completa mediante acciones normativas cuyos protagonistas - a saber, el Parlamento y, no menos intensamente, las Administraciones Públicas que ejercitan la potestad reglamentaria (arts. 66.2 y $97.1 \mathrm{CE}$ ) - persiguen y adquieren resonancia política, si se cumplen las condiciones de representación y mayoría que lo facilitan. La teoría del abuso del derecho no es un recurso fácil para censurar y reprimir eficazmente los excesos debidos a una politización de decisiones. 
Cuando ello no sucede, el Derecho objetivo se parece a un híbrido transaccional que no acierta a sintetizar lo mejor y lo más saludable de las corrientes e iniciativas que le constituyen. Es más probable que, a causa de los compromisos intermedios que preceden y acompañan a la gestación de las normas jurídicas, éstas carezcan de una paternidad inequívoca, pues cuesta averiguar si se deben al predominio de una opción de pensamiento que condesciende con otras concurrentes, o si el juicio de identidad ideológica se frustra ante lo heterogéneo de los ingredientes que intervienen en su producción.

Tales reparos justifican y avalan el recurso a una técnica de interpretación históricoevolutiva que los desvanece con el paso del tiempo. Ante los obstáculos que entonces ofrece el preservar a ultranza la voluntad del legislador, la ley — por propio impulso de emancipación - tiende a librarse de esas servidumbres y a descubrir, yendo en busca de su verdadero rostro, el espíritu y finalidad que deben animarla (art. 3.1 C.c.).

La concepción marxista del Derecho y del Estado, al igual que los regímenes reaccionarios de corte fascista, rehusaron de plano la idea de un Derecho objetivo cuyo papel no se limitase a reforzar, aún en sus versiones más descomprometidas o triviales, la carga doctrinal del sistema que le reputaba instrumento al servicio de su supervivencia y su prestigio. La impregnación ideológica del Derecho prevalece incluso cuando el hastío de la enemistad política -inconcebible en un medio donde esta consigna y la capacidad de mantenerla viva son, por definición, inagotables-o la marginación de los problemas principales de que se alimenta, dan la impresión -inexacta y desorientadora- de un achicamiento del campo en el que ese fenómeno se exterioriza con el vigor y virulencia que indefectiblemente le acompañan.

La contaminación política del Derecho se capta mejor a medida que, no obstante la devaluación de los radicalismos ideológicos, el legislador condesciende con valores y soluciones ajenos, en principio, al cuerpo de doctrina del grupo dominante del decisionismo parlamentario. Ello es así, porque importa seducir a una parte de la ciudadanía o ganarse a un sector de la opinión pública cuya actitud hostil se aplaca con concesiones u ofertas flexibles. El rigor primitivo del mensaje ideológico sufre la revisión ficticia a que fuerzan razones tácticas de proselitismo o conveniencias pragmáticas. Si las posiciones ideológicas son muy acusadas, pronto se advierte cómo el Derecho objetivo acusa con crudeza sus contradicciones, pero cabe que, otras veces, confluyan en un recinto zonas grises o reductos acromáticos — debidos al agotamiento de los filones de la ideología- y que el designio político, de mucha más difícil percepción, se intuya y/o averigue a la larga o con motivo de la experiencia aplicativa de normas inocuas a primera vista. Cabe que sólo una parte de las hi- 
pótesis u oportunidades en que se aplica la norma jurídica, exhume su intencionalidad política y, con ella, el móvil subyacente a algunas de sus posibilidades de eficacia. La noticia histórica — nutrida de precisionesclave y poco divulgadas - de la elaboración de un mandato ilumina su carga política o ideológica si, relacionada con las experiencias de su aplicación, traza la línea de causalidad y de continuidad que descubre los ocultos propósitos del legislador y demuestra la falta de generalidad de la ley. Hay preceptos — del más alto rango (art. 33.3 CE) — cuyo ciclo de debate parlamentario prueba, en vista de ciertos complementos anecdóticos, la verdad de esta proposición.

Una discreta y razonable dosis de politicidad es consecuencia de un pluralismo político que, una vez elevado al rango de valor superior del ordenamiento jurídico (art. 1.1 CE), enseña cómo, pese a los riesgos y sorpresas de esta innovación, el Derecho objetivo conserva su perspectiva de viabilidad y su garantía de funcionamiento regular. Cabe incluso que el equilibrio de un sector del ordenamiento jurídico se vea perturbado por ciertas invasiones de la justicia constitucional en el ámbito de la justicia ordinaria y que surja el dilema — con que tropezaría la segunda — de una comprensión política de la legalidad fundamental — debida a peculiaridades de composición y de estructura, que no tienen por qué darse siempre, del órgano que la esclarece (art. 159.4 CE) - y una interpretación jurídica, que únicamente se somete al imperio de la ley (art. 117.1 CE). Sumisión que apunta la sugestiva idea de un derecho de resistencia de los jueces ordinarios frente a las demasías de una lectura política del texto constitucional (art. 5.1 LOPJ).

Sin perjuicio del ingrediente de politicidad, el legislador — gravado por una responsabiblidad de sanción atenuada, pues el carácter de obligación natural impregna su albedrío, y sujeto al principio de interdicción de la arbitrariedad de los poderes públicos (art. 9.3 CE) - tiene que cohonestar su libertad decisionista con la satisfacción del bien común y las necesidades de interés general. Nociones que hay que manejar con buen acopio de sensibilidad moral y no como cobertura incontrolable de quién sabe qué iniciativas arbitrarias (arts. 128 y 155.2 CE). Nada lesiona tanto la integridad del valor superior del pluralismo político, como la frivolidad normativa de unas Administraciones Públicas ideológicamente tendenciosas o perversas y prestas a olvidar la consigna de pleno sometimiento a la ley y al Derecho (art. 103.1 CE) que se les ha cursado para paliar tales inconvenientes (art. 103.1 CE).

Los jueces ordinarios pueden utilizar la realidad política como un sumando o aspecto más de la realidad social que, concurriendo con los demás elementos interpretativos, permite conocer o actualizar la voluntad, finalidad y/o espíritu móvil de las leyes que aplican. 


\section{Condiciones históricas del Derecho objetivo}

Todo sector del ordenamiento jurídico es un producto histórico que, a causa de su dependencia de los acontecimientos, requiere la obtención de una clave o proposición que refleje convincentemente sus orientaciones e ilustre sobre el signo de su evolución.

La tesis reductora de un Derecho inmóvil fue obra de moralistas no juristas —que llamaron Derecho a la que, siendo solamente ley moral, soportaba una rotulación equívoca - y de juristas falsamente ufanos de haber erigido, en un momento dado, un ordenamiento jurídico inmune a cualesquiera cambios y agresiones. La constancia de la grandiosa inversión hecha para edificar el Estado de Derecho liberal burgués explica por qué, cautivo de un optimismo inicialmente plausible y después desautorizado por la Historia, su legislador no aceptó un Derecho de mayor excelencia que el entonces brindado a sus destinatarios, ni una sociedad más perfecta y sabiamente gobernada que la que a la sazón se organizaba en el cuadro del sistema de libertades y derechos individuales. Poco tiempo hizo falta para cerciorarse de lo relativo y falible de este aserto e intuir cuán raudos y rotundos iban a ser, en adelante, los cambios de rumbo de una sociedad cuyos reformadores le auguraban un futuro de prosperidad estable en el que erraban crasamente. Si, como maestra de la vida, la Historia había adiestrado a legislar de acuerdo con sus experimentos más recientes, su nuevo mensaje anunciaba lo perecedero y mudable del fruto de sus enseñanzas.

El referente histórico abarca, ante todo, las experiencias de aplicación de las normas de cada sector del ordenamiento jurídico. Hay una historia pretérita, cuyos sucesos instruyen y adoctrinan, cuantas veces se les utiliza como criterios clásicos de interpretación. No en vano la ley es la respuesta mayeútica a los interrogantes que, de manera expresa o tácita, le proponen aquellos a quienes se dirige su mensaje. De ahí la importancia de la información sobre la cantidad y calidad de estas aspiraciones y de cómo el legislador las ha conocido y adoptado. Los llamados antecedentes históricos y legislativos designan respectivamente los campos de la historia extranormativa y la historia normativa. Son una crónica de las carencias de la legislación, de los esfuerzos jurisprudenciales para corregirlas y de las incidencias del proceso normativo emprendido con el mismo fin. Figuran también en el —más minucioso y técnico- detalle de que daban razón las densas y exhaustivas Exposiciones de Motivos, hoy degradadas a relaciones elogiosas de la medida adoptada, literariamente empobrecidas y huérfanas de la animación y el temple filosóficos que antaño acreditaban la valía del esfuerzo del legislador y la calidad de su factura de obra bien hecha. 
Cualquier sector del ordenamiento jurídico tiene una intrahistoria constituida por los hechos singulares de cada conflicto de intereses que se pacifica aplicando las normas elegidas conforme a Derecho. Episodios que, en el plano de la acción judicial, constituyen el elemento fáctico de la causa de pedir que identifica los derechos procesales de acción y de excepción (arts. 524 I y 542 I LEC). Esta historia doméstica contribuye a que - completada con la ponderación de la equidad (art. 3.2 C.c.) - la decisión de los conflictos no se resienta de la injusticia a que conduce el uso de una norma privada de asistencia flexibilizadora.

Hay también otra historia posterior que se fragua con la acumulación de las realidades sociales peculiares de cada lugar y cada tiempo (art. 3.1 C.c.). Nada tan incómodo como el fatigoso ejercicio de lógica polivalente que consiste en definir lo que se entiende por realidad social, hasta el punto de que cualquier jurista - preguntando sobre el particular- se ve en seria dificultad y gran aprieto para responder hábilmente a tan comprometida pregunta. La realidad social, una vez localizada y aprehendida en lo que tiene de determinable, permite que las normas de un sector del ordenamiento jurídico dejen de aplicarse como, con simplicidad e imprevisión, las concibió el legislador, porque, tiempo después de su entrada en vigor, surgen otras vicisitudes a las que sus disposiciones no logran adecuarse. De ahí la atribución a los de intérpretes un poder de revisión similar al que el Derecho general de las obligaciones admite cuando, por quiebra de la presuposición o dislocación de la base del negocio, un contrato de tracto sucesivo sufre un desequilibrio provocado por el advenimiento de circunstancias - extraordinarias e imprevisibles- que alteran la equivalencia objetiva de sus prestaciones. Si la justicia o la dimensión equitativa de las normas jurídicas se ven afectadas por fenómenos de semejante signo, es forzoso corregir o interpretar modificativamente su mensaje (p. 13 EMTPC.c.).

Mucho más ambicioso es el afán de que la razón histórica de ser de un sector del ordenamiento jurídico, no sólo dependa de los capítulos de su aplicación, sino que se cuestionen el por qué y el cómo de su encaje en el complejo normativo de que forma parte. Tan difícil operación fracasa si no se desdobla en una serie de operaciones parciales, cada una de las cuales clama por su propia metodología. Hay que seleccionar, en primer término, las realidades más notables que, a juicio de los especialistas, residen en el seno de dicho sector. Hay que determinar la frecuencia estadística o la especial significación que adquieren las instituciones o la producción de los más destacados e importantes efectos jurídicos. La obtención de estos datos sirve para descubrir — si el problema de feliz idea lo autoriza y no emergen otras dificultades que lo impidan- la ley que, al expresar la evolución de un sector del ordenamiento jurídico, designa las 
tendencias generales y las desviaciones patológicas que registra el curso de sus experiencias.

Dar con la clave fisiognómica de un sector del ordenamiento jurídico significa manejar criterios cuyo mayor enojo está en lo intrépido de las operaciones interdisciplinares que llevan a su descubrimiento. Tan difícil como imprescindible es aquilatar la medida y el orden de la intervención de los juristas de sensibilidad y talante filosófico, de los cultivadores de la Ciencia del Derecho, de los expertos en distintas técnicas, de los historiadores, de los sociólogos, de los cultivadores de la sicología colectiva, de los economistas y de los reformadores sociales.

He aquí una oportunidad de reflexión sobre la asiduidad y particularidades con que se construye la Historia del Derecho. Hay sectores del ordenamiento jurídico que - como elocuentemente se dijo del instituto penal de la legítima defensa- no tienen historia o apenas cuentan con sus testimonios, porque, a la hora de ocuparse de ellos, los historiadores no les juzgan dignos de especial atención, ni les otorgan la deferencia de estudiar, con esmero y amor al oficio, el origen y evolución de sus descubrimientos. Parece que el interés en conocerlos está en razón directa de las dificultades suscitadas por el hallazgo de las fuentes y otros aspectos de la investigación y no, como resulta lógico y sensato, de la importancia intrínseca de las instituciones y del papel que juegan para promover la causa de la justicia y el bienestar social. Los historiadores del Derecho desprecian el relieve de notabilísimos fenómenos jurídicos, sólo porque su juventud les destituye del privilegio de pertenecer a la historia - como si esta excelencia dependiese de un mínimo de envejecimiento - y ofrecen la impresión de que, no obstante el atractivo de sus aportaciones, lo fácil de su investigación — que es medio para el fin perseguido- les priva de cierto componente de misterio. La Historia del Derecho tiende a despegarse del pasado inmediato y del presente porque están ahí y no se han diluido todavía, siendo así que ello elimina un obstáculo y facilita una tarea cuyos objetivos no tienen por qué asociarse sistemáticamente a la superación de esos impedimentos. La Historia del Derecho es - además de descripción del cómo más o menos se producen las normas jurídicas - testigo de la peripecia políticosocial en que han nacido y disposición de luces que facilitan los ejercicios de análisis y de comparación. Su magisterio de la vida no se limita a informar sobre el Derecho del tiempo y del lugar, sino también a insinuar la multiplicidad y riqueza de las reacciones críticas a que da lugar la observación de los fenómenos jurídicos. Las dificultades de la fase de investigación - previas al descubrimiento del objeto de análisis- concitan ciertamente elogiosos esfuerzos, pero no agotan la justificación del examen de esa realidad histórica, si, con menos obstáculos, es social y jurídicamente más 
productivo y útil atender a otros conocimientos o aspectos de que la Historia del Derecho tiende a deshacerse con alguna precipitación.

El espacio vacío se ocupa por ciertos estudios especializados — que, no proceden de los historiadores del Derecho- y por una intrahistoria tangencial que, ante la conciencia de la necesidad de suplir las insuficiencias y proponerse hacer Historia, es obra de profesionales ajenos al ámbito jurídico.

\section{Significado y aspectos de la seguridad jurídica}

Todo sector del ordenamiento jurídico presenta una estructura y densidad de contenido que explican la relación entre la seguridad jurídica formal y la seguridad jurídica material.

Cada uno de esos compartimentos se integra en un ordenamiento jurídico completo y considerado como un todo (pp. 1 y 20 EMTPC.c.). De ahí que el sistema de fuentes del Derecho objetivo asegure la plenitud o saturación de dicho ordenamiento y ahuyente el peligro de las lagunas del Derecho (p. 16 EMTPC.c.). En defecto de las fuentes primarias que abarcan la legislación en sentido material o vertical, se acude a las fuentes secundarias constituidas por el Derecho de las comunidades específicas - de ámbito local y origen consuetudinario- o de la comunidad cultural que forman los principios generales del Derecho (pp. 6 a 9 EMTPC.c. y art. 1.1 a 4 C.c.). Las normas ordinarias que gobiernan el sistema de fuentes del Derecho objetivo son, aunque nada se disponga al respecto, reglas jurídicas cuasiconstitucionales que desarrollan las garantías típicas de la seguridad jurídica (art. 9.3 CE). Ahora bien, la seguridad jurídica formal - postulado central del Estado social y democrático de Derecho, y contrapunto de sus efectivos éticos y su consigna transformadora y social (arts. 1.1 y 9.2 CE) - funciona desde ya, porque los aplicadores del Derecho objetivo trabajan con un mecanismo que no excusa - a los juristas en general y a los jueces ordinarios en particular- de responder a la duda surgida ni les priva de instrumentos aptos para dilucidarla. Ningún interesado en un conflicto queda excluido de la oferta - que el ordenamiento jurídico completo tiene a bien hacerle- de los elementos normativos precisos para beneficiarse de la efectiva tutela judicial y conseguir, a su través, una respuesta - favorable o adversa, pero siempre motivada y fundada en un razonamiento persuasivo- a la cuestión que se debate (arts. 24.1, 10.3 CE, 7.3 y 11.3 LOPJ).

La seguridad jurídica formal no va más lejos de esa garantía y poco puede, en muchos casos, a la hora de dotar a dichas decisiones de un componente de seguridad jurídica material o, con otras palabras, de res- 
tringir el uso de las fuentes secundarias — principios locales o de la comunidad cultural - cuya búsqueda y aplicación acrecientan el riesgo de error o imprecisión de los criterios que las tienen en cuenta. Los actos - judiciales y extrajudiciales - de aplicación de un sector del ordenamiento jurídico generan confianza y disipan los recelos a medida que echan mano del Derecho escrito emanado de las fuentes primarias, es decir, de la producción legislativa y de las disposiciones generales que dictan las Administraciones Públicas (arts. 66.1 y $97 \mathrm{CE}$ ). La afirmación no se degrada por el hecho de que las normas acusen dificultades comprensivas — que se salvan con la interpretación (p. 13 EMTPC.c. y art. 3.1 C.c.) - o se completan con la integración que colma las llamadas lagunas de la ley (pp. 16 y 17 EMTPC.c. y art. 4.1 y 3 C.c.). El Derecho escrito - acertadamente elegido y aplicado en medio de esas dificultades- es preferible al juego de otras normas que, en su defecto, requieren una pesquisa más fatigosa y problemática, pues a su aplicación precede siempre la dificultad de formularlas y atribuirles un supuesto fáctico con cuyo enunciado no se cuenta de antemano.

Los principios de responsabilidad e interdicción de la arbitrariedad de los poderes públicos (art. 9.3 CE) ponen a cargo de éstos una obligación natural de Derecho Público — fundada en imperativos de ética politica y ayuna de medios coercitivos de su exigibilidad- que se cumple poblando con normas escritas los sectores del ordenamiento jurídico que lo necesitan. Sólo así se logra que, reduciendo la frecuencia con que se acude a las fuentes secundarias y se ejecutan operaciones de una seguridad jurídica menor, se aborden las situaciones de interés general que inspiran la nota de generalidad de la ley —en cuanto a las personas, el espacio y el tiempo- con la vista puesta en la reacción diligente y fiable del legislador. Las conductas de omisión legislativa son doblemente censurables, pues desacreditan a la institución que abusa de su impunidad al incurrir en ellas, y perpetúan un estado de seguridad jurídica formal que frustra su conversión en otro de seguridad jurídica material. He ahí, fuera de duda, uno de los efectos secundarios y menos deseables del dogma de la soberanía parlamentaria y de la inmunidad de que el poder legislativo goza en ese punto. La parquedad o insuficiencia del desarrollo normativo - a cargo del Parlamento y del ejercicio de la potestad reglamentaria de las Administraciones Públicas- de un sector cualquiera del ordenamiento jurídico termina siendo, pese a las garantías primarias de la seguridad jurídica formal (art. 9.3), un poderoso lastre para advenir a la seguridad jurídica material que adecua la solución de los conflictos a las excelencias y ventajas del valor superior de la justicia (art. 1.1 CE). No es lo mismo proclamar la seguridad jurídica que garantizarla. Lo primero supone, que, desde una perspectiva tecnicojurídica, el sistema de fuentes del 
Derecho objetivo nunca peca de insuficiente o arbitrario (cap. $10^{\circ}$ TPC.c). Lo segundo implica que, no bastando esto, se precisa de un esfuerzo incesante para inundar el ordenamiento jurídico con la legislación que mitiga el riesgo de arbitrariedad en que puede incurrirse al decidir las contiendas privativas de cada sector, y refuerza la efectividad de la tutela judicial obtenida con ayuda de esos instrumentos (art. 24.1 CE). Se ha de tender al achicamiento del espacio irregulado en que la costumbre y los principios generales del Derecho cumplen un papel cuyos inconvenientes se corrigen gracias a acciones normativas que mejoran la calidad de la plenitud del ordenamiento jurídico.

Si la inseguridad jurídica formal pervive a causa de la utilización frecuente de las fuentes secundarias, la insuficiencia resultante se atenúa por obra de una reacción social adecuada. Los particulares y los grupos sociales —ávidos de una dosis mayor de seguridad jurídica materialno se resignan a que sus diferencias se ventilen acudiendo a esas fuentes, sólo porque el legislador no se ha esmerado en evitarlo. Se deciden a construir otros ordenamientos concéntricos o periféricos, cuya regulación aborda con rigor los problemas que, de lo contrario, se exponen a un insatisfactorio tratamiento. La formación de círculos contractuales - creadores de un Derecho autónomo con fuerza de ley entre quienes lo pactan (art. 1.091 C.c.) - es la expresión más instintiva y simple de esta actitud de resistencia crítica. Descansa en un criterio de eficiencia, partidario de que las soluciones normativas se adopten por los sujetos cuya inmediación al problema y cabal conocimiento de causa les sitúan en condiciones óptimas para dar con la respuesta más ajustada a sus características. La proliferación de esta tendencia coloca a los poderes públicos en una postura de subsidiariedad que, unas veces, sanciona su inacción y, otras, no es el estímulo más recomendable para su acción positiva.

Crece y se robustece la tendencia a que estos ordenamientos ganen en complejidad y amplitud, hasta el punto de erigirse en verdaderos $D e$ rechos generales y ofrecer la impresión de que recrean estados de cosas que sólo tienen un falso mimetismo con otras situaciones históricas superadas por las adquisiciones del Estado de Derecho. El empeño universal y sistemático del proceso codificador liquidó los reductos particularistas de Derechos locales sin rigor ni fuste científico, plagados de lagunas, interferencias y contradicciones. Aportó soluciones cuyo acierto técnicojurídico constituía una excelencia que era el mejor certificado de su acercamiento a la justicia. El fenómeno actual de formación de nuevos ordenamientos jurídicos refleja una apariencia coincidente con la de los desacreditados particularismos de antaño. No es empero un retorno a los vicios entonces censurados, sino un arbitrio superador de las carencias que acusa la legislación, a causa de las restricciones económicas, de los con- 
dicionamientos impuestos por el principio de generalidad de las leyes y de la lentitud de las operaciones de desarrollo legislativo. El crédito de esos ordenamientos depende de la calidad y eficacia de sus soluciones, contrafigura de lo que la improvisación y el casuismo de los viejos Derechos locales representaron en su tiempo. Su emergencia se asemeja a un voto de castigo para el legislador inactivo, cuya constitución en mora se sanciona por medio de una autonomía que, con todos sus yerros y limitaciones, se difunda y elogia como jurídicamente gratificante y eficaz.

No faltan ámbitos penetrados por principios pragmáticos - porque considerarlos deontológicos tiene lo suyo de sarcástico- que rigen las conductas básicas de quienes los habitan. Ciertos agentes de la vida económica han pactado unas reglas de juego que vedan censurar las decisiones del poder, denunciar los vicios de la propia comunidad, entregarse a aventuras políticas y ceder a tentaciones de dirección e ingerencia en los medios de comunicación. Todo un código de discreción y sobriedad al servicio de la inmensidad e inmunidad del lucro económico.

El Derecho de las relaciones de trabajo acusa de modo especial esta tendencia. La autonomía colectiva — que es a las formas sindicales de negociación lo que la autonomía privada a la diversidad de estipulaciones contractuales (arts. 1.254 y 1.255 C.c.) — crea un vasto ordenamiento extraestatal que agrupa las adquisiciones de la negociación colectiva. Ordenamiento poblado por normas generales que, en cada unidad de contratación o ámbito funcional, tienen cuerpo de contrato - a causa del mecanismo de su producción-y alma de ley, por obra de la llamada eficacia general (arts. 37.1 CE y 82.1 ET). Esta supone que las condiciones normativas negociadas no limitan su vigencia y obligatoriedad a los trabajadores integrados en los sindicatos que las han acordado, sino que las amplían a los sindicatos no negociadores y a cuantos, ejercitando la libertad de no pertenecer a sindicato alguno, las ven incorporadas al contenido de cada contrato individual de trabajo. (art. $3.1 b$ ET).

\section{Selección y renovación de los intereses protegidos jurídicamente}

Todo sector del ordenamiento jurídico se caracteriza en virtud de los intereses tutelados por su acervo de normas y del ritmo de su renovación o subsistencia.

El interés es la inclinación a la utilidad o beneficio que cada persona individual extrae del contacto con un bien o del goce de una situación que disfruta y aspira a conservar. El interés pertenece al siquismo de apetición del sujeto, cuya inmoderación innata — patente y muy visible en las reacciones elementales de la infancia- pretende poseer ilimitadamente, 
sin prejuzgar lo lícito de la adquisición ni admitir las limitaciones del goce deseado. Se quiere que estos límites se minimicen o desvanezcan cuanto antes. La tesis pesimista del pacto social va en busca de arbitrios bastantes para dificultar que el crecimiento galopante de los instintos egoístas y la torpe voracidad del hombre instintivo favorezcan la preponderancia — asoladora de la vida de la familia humana - de los más poderosos sobre los inermes y desposeídos.

La omnipotencia del Derecho - que es un ideal en permanente trance de erosión y descrédito - no ha conseguido poner fin a las inclinaciones egoístas y, en cambio, ha cooperado, contra su propósito, a agotar sus depredaciones más penosas. El interés se modera mediante la acción racionalizadora de las normas de Derecho objetivo que, en cada sector del ordenamiento jurídico, proveen al reparto de esa utilidad y moderan las demasías del apetito incontrolado. La libertad ocupa lugar y el Derecho asume su administración en términos sin los que se hace inviable la actuación regular y provechosa de sus distintas facultades. El Derecho subjetivo o la situación jurídica — caracterizados por el derecho de acción procesal que se reconoce para protegerlos (art. 24.1 y $117.1 \mathrm{CE}$ )proviene de las operaciones con que el poder público aquilata el interés que, en cada caso, la persona reivindica y defiende como parte de su acervo de bienes más preciados.

La noción de interés designa la utilidad o provecho anejo a la posesión de un bien o de un valor, si ambas nociones se entienden en sentido estricto. Sabido es que, en sentido amplio, un bien es cuanto gratifica y hace más deseables las expectativas de una existencia personal que cuenta con su contribución. El bien - distinto de la categoría de lo bueno en algunas de sus expresiones- equivale a una realidad objetiva y cognoscible por medio de la sensibilidad externa, la cual capta la realidad y adivina las vicisitudes que positiva o negativamente le afectan. Cabe que dicha realidad - de que, entre otras muchas, son expresiones tangibles la vida personal y la propiedad privada (arts. 15 y 33.1 CE) — se vea tutelada por un sector del ordenamiento jurídico y que, a causa de su accesibilidad sensorial, no haya dificultad en comprobar los atentados de que un bien es objeto y las acciones con que, reaccionando en pro de su rehabilitación e integridad, el Derecho se pone a su servicio. Cuando el Derecho se desentiende de un bien de ese carácter, la impunidad — sensiblemente conocida- de las agresiones que sufre y la evidencia de su desprotección muestran la clamorosa indefensión que le aqueja después de todo ello. El interés — anejo a la posesión del bien desprotegido- se ve privado del amparo que provocaba la acción del Derecho en garantía de su conservación y accesibilidad.

Otro es el interés que encarnan los valores o bienes inmateriales, porque su percepción no depende de la sensibilidad externa y sí del si- 
quismo interior de carácter intelectual y emotivo. Un valor se comprende y se siente merced a la síntesis de la inclinación espontánea y la concepción natural de su significado. Valores como la solidaridad de las personas y las comunidades, el sentimiento de pertenencia localista, la afección confesional o religiosa, la conciencia de adscripción a un grupo social, y la lealtad a que obliga, pueblan un mundo cultural — que ha permitido adquirirlos y recoger sus frutos-cuya realidad no es tangible y cuya entidad, lejos de mantenerse inalterada, se debe a la continuidad y entereza con que la conciencia y la emoción colectivas sirven de apoyo al valor en que consiste. Sustento del que, en definitiva, depende su salvación o su condena.

Amén de la asistencia - favorable al crédito de los valores e indispensable para su prosperidad y afianzamiento- del sentimiento individual y colectivo, la ayuda del Derecho - cuya tutela abarca el espacio habitado por cada valor digno de estima - no sólo le inmuniza frente a las agresiones, sino que significa un plus de testimonio cultural en pro de su supervivencia. La desprotección jurídica de un valor le hiere de muerte, porque el abandono del Derecho — que de él se desvincula — rebaja y, con el tiempo, anula todo el aprecio social de que venía disfrutando. Si esta marginación no se compensa - lo cual es improbable- con acciones sociales de rescate del valor afectado, sus oportunidades de perdurar apenas cuentan.

Cada sector del ordenamiento jurídico tiene a su cargo un haz de intereses constitutivos de los bienes y/o valores que debe ordenar y repartir equitativamente. Su identidad, cantidad y calidad dependen de la fisonomía - tradicional, progresista o ecléctica- de la disciplina que ha dado nombre a la correspondiente rama del Derecho. Alecciona la comparación que, para subrayar sus rasgos diferenciales, se ha entablado entre el Derecho Romano, el Derecho Civil y el Derecho de las relaciones de trabajo. El Derecho Romano ofrece la imagen de un varón anciano y experimentado, cuyas admoniciones y consejos convierten el pasado en un depósito de sabios aleccionamientos sobre todo aquello que, en cualquier circunstancia, se impone a causa de su calidad y del crédito probado de sus soluciones. El Derecho Civil se parece a un moderno y ejecutivo triunfador, ufano de sus éxitos y capacidades, que se precia de encarar con arrojo y superar con fortuna las situaciones de adversidad o incertidumbre. El Derecho de las relaciones de trabajo trae a la memoria la personalidad bulliciosa de un joven, no necesariamente alborotado y sí excitado por nuevos desafíos, sin apenas margen para intelectualizar sus experiencias y obligado a los cambios de oficio - no en vano la crisis ha caracterizado la formación y evolución de este sector del ordenamiento jurídico-que traen consigo los nuevos signos de los tiempos. 
Son distintos los ritmos de implantación, sobrevivencia y renovación a que los intereses se sujetan en cada sector del ordenamiento jurídico. Unos de ellos proclaman, con orgullo, que el núcleo originario de intereses - que configura su fisonomía - no ha mudado de signo y contenido, aunque admita adiciones o enriquecimientos debidos a la inevitabilidad de los cambios históricos y al efecto regenerador del conflicto social. De algunas de esas disciplinas se desgajan ramas que, a causa de lo novedoso del interés protegible, pretenden una independencia que el transcurso del tiempo se encarga de condenar al fracaso o de premiar con un resultado feliz.

Otras ramas del Derecho funcionan a un ritmo de renovación que revela su compromiso con las exigencias de la modernidad y el cambio social, pues hace falta una disposición atenta y vigilante para intuir los nuevos intereses y no confundirlos con fenómenos de falsa seducción o espejismos con apariencia de los que no son tales. Hay sectores del ordenamiento jurídico - los más sensibles al impacto de estas transformaciones- en que a los intereses protegidos hasta un momento dado suceden otros que, ante la fuerza de las cosas, hacen de la crisis — entendida como desconcierto y sorpresa intelectual que cuestiona el recurso a los viejos métodos y duda de lo incierto de un impredecible porvenir - una constante redefinidora de la evolución de la rama del Derecho afectada.

\section{Presupuestos idealistas y utilitaristas del Derecho objetivo}

Todo sector del ordenamiento jurídico se señala por la necesidad de responder a una demanda social que, para ser tal y no su contrafigura, debe conectarse con las exigencias del interés general y, en su caso, con los postulados de un Derecho justo.

El acceso a las soluciones de un Derecho justo fue un lugar convergente del esfuerzo de moralistas y juristas, hasta que el positivismo constitucional —introductor de los derechos inalienables del sujeto-y el hecho codificador - que recogió las fórmulas jurídicas más distinguidas y solventes- mostraron cómo, al ser lo mejor enemigo de lo bueno, valía la pena conformarse - social e individualmente - con el auxilio de un Derecho válido y pródigo en soluciones útiles para resolver los problemas que su aplicación evitaba o corregía. El positivismo legalista depuró lo confuso y caótico de la legislación, pero, a medida que estrenaba sus nuevos modelos, intuía los inconvenientes que de su rigidez se derivaban. Tales operaciones revelaron - pasando de la sorpresa a la inquietud- que, pese a la omniprovidencia del legislador, las transformaciones sociales las inutilizaban. Si una sola palabra de aquél podía convertir en 
material de desecho bibliotecas enteras, un sesgo decisivo de la realidad social degradaba buena parte de la obra legislativa a un cuerpo de Derecho inútil o abolido.

Se explica así la idea — prudente y elogiable — de que el legislador no puede acometer su tarea sin ponderar la realidad social, cuya valoración - dirigida a constatar la solidaridad o voluntad de los componentes de la comunidad y, en definitiva, del pueblo del que fluye el sentimiento de justicia (art. 117.1 CE) - requiere dosis poco comunes de delicadeza y diligencia. La ley no puede reducirse a un producto residual a corto plazo y necesita un tanto de flexibilidad y adaptación a los cambios sociales, antes incluso de que las interpretaciones correctoras llamen en su auxilio a la realidad social como criterio de interpretación. La ley flexible perpetúa la voluntad del legislador que previamente cuida de no incurrir ni acantonarse en un inmovilismo estéril. De no ser así, se acelera el fenómeno - hermenéuticamente inevitable - de la sustitución de la voluntad del legislador por la voluntad de la ley que adquiere un espíritu y finalidad (art. 3.1 C.c.) a los que fundamentalmente - es decir, anteponiendo y reforzando su significación- debe atender su aplicación, sin que sobre ellos prevalezcan los demás elementos interpretativos.

Una postura radical sostiene que, pese a todas estas consideraciones, cualquier demanda social tiene que provocar la respuesta del legislador y obligarle a satisfacer sus requerimientos. Parece que, al margen de toda facultad depuradora o selectiva, debe reaccionar con un automatismo que le priva de adoptar actitudes críticas frente a semejantes peticiones. Una suerte de mercader al por menor, urgido a la acumulación y despacho del género que se le solicita, sin oportunidad de comprobar sus calidades de obra bien hecha. No es eso. La tesis de que cada sector del ordenamiento jurídico se construye a medida de la demanda social requiere alguna indicación complementaria.

Conviene, ante todo, precisar lo que se entiende por demanda social. No es cualquier petición - aún masiva o espectacularmente extensaque provenga de un grupo significativo o importante, porque su grado de razonabilidad - que suele coincidir con lo impresionante de su formulación - no siempre está en razón directa de ese dato. Abundan las demandas sociales menos razonables o cuya irrazonabilidad basta para que el legislador desista de ocuparse de ellas. Hay que escindir - como se separa la paja del trigo- las verdaderas de las falsas demandas sociales. La pretensión de que toda demanda social es obligadamente atendible, conmina a presumir que, por hipótesis, cualquiera de los clamores en que se traduce, rebosa sensatez y cordura. Desde que el positivismo juridicopenal reparó en el potencial delictivo de las multitudes, los fenómenos de perversión y/o seducción colectivas y las técnicas de aleccionamiento de masas — con fines, a veces, inconfesables - relativizan tal afirma- 
ción y prueban cómo una comunidad puede esconder propósitos y abundar en propuestas incompatibles, por detestables y descabelladas, con las soluciones que se les oponen y las desautorizan.

El criterio para concluir si una demanda social es tal y, por ende, verdadera y fiable, depende de su coincidencia con los objetivos de interés general o, más propiamente, con alguno de los intereses generales confiados a la tutela de la ley. El interés general constituye un concepto evanescente, tras cuyo pretexto el legislador puede escudarse para sugerir soluciones sustraídas a toda posibilidad de control, pues es difícil demostrar convincentemente que no media en un caso determinado y fijar la frontera entre las situaciones que le implican y las que no denotan su presencia ni acusan su necesidad. Los intereses generales se atienen a un principio de delimitación que permite graduar la objetividad con que son servidos por las Administraciones Públicas (art. 103.1 CE) y, con mayor razón, valorar las iniciativas del legislador que, a la vista de las relaciones que abarcan, encuentra en ellos la razón de ser y justificación de la generalidad de las normas jurídicas que elabora (art. 67.2 CE). Allí donde surge un problema sobre las exigencias de la coexistencia de las personas y grupos sociales, de la colaboración entre unos y/u otros, y de la participación en los bienes colectivos, se incide en los aspectos de la noción de bien común y se suscita una cuestión que atañe a esos intereses generales. La opinión sobre la juricidad y necesidad de la demanda social es una condición — a que el legislador debe atenerse en trance de aceptarla o rehusarla- similar a la que tienen en cuenta los jueces ordinarios para determinar si concurren los requisitos de una norma jurídica de Derecho consuetudinario (art. 1.1 y 3 II C.c.).

A la razonabilidad del interés - en cuanto general o extensivo a una suma de personas, que ocasionalmente forman un grupo social, o a una comunidad consolidada y estable - se añade la exigencia, no menos importante, de que la protección conferida por las normas de un sector del ordenamiento jurídico se adapte a los principios y preceptos constitucionales (arts. 1.1, 9.3, 66.2 y 97.1 CE). De ahí lo provechoso de las lecturas preventivas que, aun sin ser el intérprete nato de la legalidad fundamental (arts. 159.1 CE y 1.1 LOTC), ha de hacer el legislador ordinario para que las leyes no adolezcan de inconstitucionalidad. El enaltecimiento de este esfuerzo justifica el deber judicial de propugnar la interpretación proconstitucional de las normas con rango de ley que, a primera vista, incurren en dicho defecto (art. 5.3 LOPJ).

Ante lo enojoso de la tentativa de fijar la dosis de justicia de las normas jurídicas, los legisladores positivos — propensos a sortear escollos axiológicos- se concertaron tácitamente para construir un Derecho al que, en lugar de apellidarle justo, se atribuyó la excelencia de ser el más conveniente al bienestar y la satisfacción de las necesidades de aquellos a 
quienes iba dirigido. El cambio de etiqueta eludía la dificultad de coincidir en los referentes pacíficamente utilizables para emprender una tarea cuyo éxito dudoso no compensaba las ventajas de algunos de los estímulos que la movilizaban. Contraer el compromiso de facilitar - además de un Derecho válido y útil - un Derecho justo contrariaba el buen sentido de la máxima prudencialista, según la cual lo mejor era enemigo de lo bueno.

Algún ordenamiento jurídico - especialmente audaz- puede desdecirse de esa actitud minimalista y admitir que el Derecho óptimo emane de un proceso que conjugue la legitimidad de sus orígenes y las garantías tecnicojurídicas de su producción. Así sucede cuando el valor superior de la justicia se erige en condición informadora de cuantas soluciones llevan la impronta del Derecho del Estado (art. 1.1 CE). A los requisitos indicados —de razonabilidad y constitucionalidad de las propuestas que hace la demanda social expresa o tácita - se añade el de la justicia de su solución. Conclusión a que también se llega advirtiendo que la justicia - como sentimiento rectamente ordenado a procurar el bien común y no a satisfacer los desvaríos o aberraciones colectivos - procede del pueblo y que el Parlamento - que le representa- debe trasladar este clamor primario a las leyes en que se plasma su realización (arts. 1.2, 66.1 y 117.1 CE). He aquí un componente idealista que enriquece las condiciones comúnmente exigidas para la selección y tutela de los intereses que el Derecho objetivo se apropia y cuida de racionalizar.

Se pregunta qué es lo justo para el legislador cuya tarea se ha visto así afectada. Hay una regla elemental que, a fuer de simplificadora, responde a esta cuestión. La solución de un problema de interés general es justa cuando la opinión pública - esclarecida y activa, como reza una regla ya clásica, y no desinformada y apática-entiende que no se puede aplazar, sin grave daño, la solución de que se trate. Hay razones de peso para rehusar a un proyecto la cualidad de justo, si la opinión juzga que su tratamiento y ejecución pueden demorarse sin que cunda la alarma social, ni se dañen los intereses en juego. La opinión pública va, a no dudarlo, a reputar injustas las medidas que suspendan el régimen del derecho de propiedad privada, la ordenación de las relaciones contractuales o el sistema de garantías de los particulares frente a las Administraciones Públicas (arts. 33.1 y 106.3 CE). Puede entender, sin desatino, que el valor superior de la justicia no padece si se pospone el tratamiento legislativo de las uniones de hecho, e incluso defender que se conculca asignando a este fenómeno un régimen jurídico que pugne con el respeto debido al íntegro desarrollo de la personalidad (arts. 10.1 y 27.2 CE).

Es una petición de principio - errónea y peligrosa- defender que toda demanda social apareja la justicia de sus reclamaciones. Muchas de ellas presentan un rostro aberrante que las destituye de la razonabilidad 
más rudimentaria y descalifica sus afanes de reconocimiento y protección legislativos. No se da siempre una correlación automática entre la respetabilidad de la demanda social, la razonabilidad de su propuesta y la generalidad de la norma jurídica dictada para proveer a sus solicitudes. La justicia de la solución es una exigencia más que debe ponderarse. La razonabilidad de la medida y el carácter general de la ley se legitiman por lo urgente y deseable de una regulación destinada a los componentes de un grupo social o comunidad, cuyo interés colectivo es notorio y despierta una mala conciencia que no se libera mientras el problema surgido de su comprobación siga irresuelto. El legislador no ha de perder de vista - como elemento adicional de certeza - la dimensión estadística de un dato sin el que es imposible seleccionar las verdaderas demandas sociales y prescindir de las que no lo son. Si los jueces ordinarios atienden a la legitimidad del interés objeto de una efectiva tutela judicial (art. 24.1 CE), los legisladores se enfrentan al reto de la generalidad de los intereses, cuyas dificultades de especificación — como concepto jurídico indeterminado- no eximen de un delicado análisis de las condiciones de admisibilidad de la demanda social que sólo a ellos debe acomodarse.

La exigencia de un Derecho justo es una más de las restricciones que sufre el dogma de la soberanía parlamentaria. Parece discutible, en tales casos, presumir la justicia de todo el Derecho emanado de la acción normativa de los poderes públicos. Basta con el descargo consistente en presumir la constitucionalidad específica de sus soluciones y predicar de ellas una interpretación proconstitucional que salve los vacíos o lagunas irrecomendables. Los trabajos preparatorios de la legislación no tienen por qué justificar —esto es demostrar la justicia - de las medidas legislativas que la conciencia social reclama abrumadoramente como esperadas y exigidas. Puede haber una suerte de justicia notoria que se postula y aguarda con algún clamor. Si no es así, el legislador debe cumplir la carga de comunicar - para no merecer el reproche de un voluntarismo político a ultranzalas razones - necesariamente persuasivas e irreductibles a un cúmulo de lugares comunes - por las que estima justa una medida con la que, de entrada, la opinión pública no comulga fervorosamente y de cuya adopción no se muestra incondicionalmente partidaria.

\section{Reducción de las tensiones del conflicto social}

Todo sector del ordenamiento jurídico cumple una función determinada en el seno del conflicto social.

Los grupos sociales en que el individuo se integra (art. 9.2 CE) y cuyo todo constituye, a diferencia de la sociedad monista y uniforme de 
antaño, la sociedad pluralista de hoy día, ocupan un espacio habitable en el que las fricciones e interferencias son ineludibles. El mismo Derecho, que quiere poner diques a las acciones aberrantes o desmesuradas de expansión, no logra contener la espontaneidad de ese conflicto y, para conservar su prestigio normativo, debe huir de previsiones y remedios que, frente al empuje y contundencia de aquél, no van a surtir el efecto deseado. Los grupos sociales viven en conflicto porque la libertad ocupa lugar y aún la movilidad más respetable pugna con la de otros grupos, amén de los conflictos potenciales que comunidades competitivas - de posterior aparición- escenifican en tantos ámbitos cuyo acaparamiento se disputan.

El conflicto de los grupos sociales es irrenunciable, porque ninguno de ellos se resigna a abandonar el propósito de progreso que forma parte de esa representación. Es eficaz en la medida que - gracias al poder evocador de la máxima de que la guerra y la contradicción lo engendran todo - su interminable mal de crecimiento constituye la clave de un esfuerzo de liberación que, además de contar con el protagonismo de los sujetos sociales que asumen sus cargas, recibe, si es del caso, el apoyo de los poderes públicos (art. 9.2 CE). Es natural, ya que su existencia y reconocimiento pertenecen a la esencia misma de las cosas y su subsistencia queda herida de muerte si no se conservan los moderados niveles de tensión que le caracterizan.

He ahí la traza del conflicto social -irrenunciable, eficaz y natural- de cuyas variantes se ocupan unos u otros sectores del ordenamiento jurídico o, por mejor decir, cuya evidencia está en la base de las acciones legislativas que, como dato común a todas las realidades sociales, presuponen su evidencia e inexorabilidad.

El Derecho dedica su atención a los conflictos sociales para valorar las consecuencias del ejercicio de la libertad que a ellos subyace. Reacciona según la fuerza creadora del hecho conflictivo. Hay conflictos sociales cuyos agentes son grupos de protagonismo apático, a los que el Derecho dota de impulso suficiente para la reanimación y el estímulo de sus libertades, aunque, a la vez, haya de regular algunas de sus peripecias y suplir las omisiones de sus protagonistas. Hay conflictos sociales de vibración ponderada, a los que el sector correspondiente del ordenamiento jurídico no pierde de vista ni deja de la mano. La necesidad de intervenir surge porque sus personajes son particularmente activos y propensos a posturas polémicas que reclaman el paliativo frecuente del Derecho. Hay, finalmente, conflictos sociales de dinámica torrencial que, en nombre de su autonomía y pretensión de libertad, se oponen a cualquier regulación jurídica. Ello, por sí solo, no basta para descartar la oportunidad de que el De- 
recho intervenga, pero le obliga a actitudes de cautela que, sin atentar contra la autorregulación del conflicto, administran algunas de sus incidencias.

Cuando un conflicto social rebasa los límites propios de su tensión connatural, se descompensan las libertades que le son inherentes y que el Derecho debe proteger. La paz social se desvanece y decae el mínimo de condiciones necesarias para que aquellas se realicen en el régimen de paz, solidaridad y justa distribución de los bienes y/o valores cuya adquisición y goce quiere asegurarse.

Algo hay que subrayar sobre lo que, a diferencia del conflicto social, significan los conflictos interpersonales. Los conflictos sociales convienen al progreso normal de los grupos humanos, desde que el quietismo ingenuo de los antiguos reformadores sociales dio paso a la idea de que todo evoluciona implicablemente y que el tiempo puede hacer de las más acertadas adquisiciones jurídicas, algo inútil, perverso e irreconocible. El Derecho común se ocupa de cuantos acontecimientos son, pese a sus dimensiones conflictivas, compatibles con un proyecto de normalidad. El conflicto social no se destina, salvo en el caso de exacerbación de sus tensiones, a desaparecer, sino a prosperar como cauce de liberación de los grupos y de las personas que en ellos se integran (art. 9.2 CE). Todo, pues, lo contrario de la fisonomía del conflicto individual. La negación de la paz en la vida individual de relación reclama la mediación coactiva del Derecho para liquidar las agresiones que, grandes o pequeñas, siempre son un vejamen para la causa del mundo del espíritu. La persona humana las sufre en lo más hondo de sí misma, tanto a causa de su impacto instantáneo, cuanto del estado de cosas que surge de su concurrencia y del daño irrogado al proyecto de vida en dignidad, si no se pone coto a las situaciones de agravio y las servidumbres que esa actitud hostil entraña. El conflicto individual pertenece a la patología de la existencia humana, pugna con el principio de que cabe vivir en paz con todos si la buena voluntad y la recta intención de cada uno se lo propone seriamente, y espera del Derecho el urgente remedio de los males que encarna.

La coasimilación de ambas especies de conflicto es la clave del equilibrio y la prosperidad sociales, pero el Derecho - que gestiona, y no puede reprimir los conflictos normalizados- debe prever fórmulas cuyo poder de disuasión consiga que los individuos eludan y repudien por sistema las formas de conflicto interpersonal —ocultas tras las más inofensivas apariencias- y se integren en grupos que, al protagonizar conflictos sociales, cumplen funciones que cada sector del ordenamiento jurídico promueve y regula de acuerdo con la modalidad que representan. 


\section{Condiciones económicas del Derecho objetivo}

Todo sector del ordenamiento jurídico se caracteriza por la sinceridad e intensidad con que propicia el ejercicio de las libertades o, al contrario, da entrada a situaciones que las desnaturalizan o restringen.

Las libertades propias de cualquiera de esos compartimentos existen para crecer y desarrollarse en un clima de autorregulación o atribución al sujeto de la oportunidad y la excelencia de establecer la amplitud y los límites de su disfrute. La perspectiva transformadora de una libertad efectiva (art. 9.2 CE) conviene a este propósito. La declaración legislativa de sus contenidos sólo tiene sentido en situaciones de apatía - cuando no hay otro modo de mostrar a una comunidad, desentrenada en su ejercicio, las vías de su adquisición o rescate- o, en hipótesis de depresión, si las desigualdades entre grupos sociales privan de reaccionar con la energía necesaria para la conquista y defensa de las libertades. Quizás las reglas de reserva de ley - previstas para el desarrollo legislativo (art. 53.3 CE) - atiendan menos a la construcción positiva del contenido de las libertades y miren preferentemente al principio general de colimitación de los derechos (art. 10.1 CE), facilitando que la inmunidad de su contenido esencial o núcleo invulnerable se consiga con el cumplimiento de esa condición.

A todo derecho es inherente la autorregulación de las facultades que lo integran, para acentuar sus capacidades de progreso y aproximarse al objetivo de vivir en dignidad. Vivir en dignidad es organizar una existencia en que la persona ejercita su función cosmoeminente o de supremacía sobre el resto de las cosas que pueblan el mundo y están a su servicio, sin que ello signifique la plena servidumbre de ellas ni la dominación absoluta del sujeto que las utiliza. Se llega a vivir en dignidad cuando el ejercicio de las libertades concilia la idea de que todas ellas ocupan lugar con el respeto de las condiciones básicas que el Derecho ha fijado para satisfacerlas. Armonía que no está reñida con la multiplicación de los conflictos inseparables del mal de crecimiento de las comunidades que persiguen sus metas de igualdad y libertad en el cuerpo total o universo de la sociedad pluralista (arts. 9.2, 20.3 y cap. $3 .^{\circ}$, tít. I, CE).

Frente a lo grato y elogiable de esta realidad, hay sectores del ordenamiento jurídico en que las regulaciones del Derecho preponderan sobre las aspiraciones expansivas de la libertad. Ello ocurre si la propia naturaleza de las normas - pertenecientes al Derecho Público- prohíbe dejar al arbitrio de los particulares la implantación de un sistema autónomo de regulaciones. Se intensifica a causa de la pretensión - que también acota los espacios libres de las disciplinas de Derecho Privado- de vigilar con algún celo el ejercicio de la autonomía privada. Es entonces 
cuando las normas de orden público cumplen, más o menos drásticamente, sus cometidos de guarda y rectificación.

El orden público es el Derecho necesario formado por las normas que componen el orden público textual y por los principios constitutivos del orden público virtual, a través de normas impositivas - contrapuestas al Derecho disponible por los particulares- que pueden consistir en mandatos, propios de las normas imperativas, e interdicciones, características de las normas prohibitivas (arts. 6.2 y 1.255 C.c). Aun así, hay una concepción liberal y otra autoritaria de lo que representa el orden público. La primera cuida de preservar las expresiones de autonomía compatibles con la acción correctora del Derecho necesario y sostiene que el homenaje al ejercicio de la libertad requiere amparar, por encima de todo, un valor que no puede verse inexorablemente aniquilado. La segunda defiende que el orden público debe reaccionar enérgicamente ante cualquier exceso de libertad que ignore sus prohibiciones y/o mandatos, sin dejar a salvo atisbo alguno del esfuerzo creador que se consume.

\section{Condiciones económicas del Derecho objetivo}

Todo sector del ordenamiento jurídico mantiene una relación de dependencia con los hechos de naturaleza económica y con los signos generales de la economía.

Los sistemas de Derecho objetivo y las situaciones jurídicas consiguientes no hicieron, en principio, de la economía un dato determinante de sus soluciones. Ignoraron la utilidad y la idea de una política económica que informando la acción de los poderes públicos, definiese sus criterios al respecto y adoptase, en su caso, las oportunas decisiones de intervención y dirección. Los hechos económicos surgieron con el ejercicio de los derechos individuales, cuya deficiencia igualatoria robusteció un poder de grueso calibre y engendró problemas sociales de gran envergadura. Lo económico resultaba de un juego espontáneo de las fuerzas sociales que los poderes públicos — fieles a las consignas de la filosofía liberal- no podían mediatizar o reducir.

Las tesis del materialismo dialéctico y del determinismo económico avisaron del peligro de la indiferencia de los ordenamientos jurídicos que se despreocupaban y desvinculaban de esas realidades. Surgió luego el convencimiento de que la economía no suponía un accidente más en la protección de otros bienes y valores jurídicos, sino que poseía sustantividad bastante para constituir un fenómeno al que el Derecho debía prestar atención. Algunos sectores, cuando menos, del ordenamiento jurídico no podían mostrarse insensibles a las repercusiones múltiples de 
los hechos económicos ni prescindir de ciertos presupuestos que les eran anejos.

Los sistemas autoritarios de corte fascista pusieron el proyecto económico a la cabeza de sus objetivos de regeneración nacional. Construyeron una teoría geopolítica, que pretextaba sus necesidades para facilitar la expansión territorial y la depredación de los espacios afectados, y crearon un Derecho de la economía que agrupó estratégicamente los sectores del ordenamiento jurídico cuya coordinación era precisa para conseguir dichos fines.

El Estado social de Derecho hizo suya — para salvar una de las carencias del extinto Estado de Derecho liberal burgués- la figura de los derechos económicos y sociales y enriqueció los sectores del ordenamiento jurídico que se aprovecharon de su recepción. De ahí la aparición de una política cuya expresión normativa reside en esos campos y se concibe como simultáneamente social y económica. Lo primero, porque, rompiendo el marco de los clásicos derechos individuales, concierne al bienestar y progreso de grupos sociales cuya difusión de intereses se sustituye por los bloques definidos de intereses que reconoce la legislación (cap. 3. ${ }^{\circ}$, tít. I CE). Lo segundo, porque el acceso a los nuevos derechos y la plenitud de su goce no sólo dependen de la inhibición del poder público que respeta los ámbitos de libertad en que se satisfacen. Hay que implementar fórmulas de financiación y soluciones económicas aptas para la efectiva realización de los derechos y la adquisición de los bienes en que su objeto material consiste.

La irrupción del Estado de bienestar generó el compromiso de que los poderes públicos garantizasen - en forma específica o con compensaciones adecuadas - la tutela de la existencia personal, pues cada futuro individual equivalía a un bien cuya pérdida determinaba un daño y acarreaba su reparación. El Estado de bienestar adoptó la tesis del presupuesto comprometido, para que la relación de gastos públicos se ocupase de semejantes fines y el capítulo de ingresos reflejase su necesidad. Cada sector del ordenamiento jurídico en que repercute la política social, se somete a un principio de limitación de recursos que restringe económicamente los proyectos de expansión y crecimiento de las atenciones brindadas al cuerpo social. El feroz fuero de la economía determina, no obstante, que valiosas adquisiciones sociales - como el principio de irregresividad en los niveles de tutela logrados por ciertos sectores del ordenamiento jurídico - hayan decaído e impuesto sacrificios que urgen a conciliar las exigencias de la justicia distributiva y los postulados de la solidaridad.

La penetración gradual de lo económico en los dominios del Derecho explica la importancia del concepto de orden público económico, cuyas 
normas marcan la orientación con que se aplica un sector del ordenamiento jurídico, o forman parte de un Derecho necesario que prima sobre los pactos entre particulares. El orden público económico no suplanta la iniciativa privada, sino que la modera para tutelar la productividad de acuerdo con las condiciones de la economía general, que constituyen el primer rango de limitaciones, o las necesidades de una planificación democrática a que, en su caso, hay que acudir (art. $38 \mathrm{CE}$ ).

La realidad económica - concretada en las apreciaciones técnicas de los especialistas o la notoriedad de sus más aspectos más sensiblespertenece a la realidad social del tiempo y del lugar. Da juego como elemento historicoevolutivo de interpretación que, habida cuenta de su impacto, permite acomodar ciertas normas jurídicas a las nuevas circunstancias creadas por su superveniencia (art. 3.1 C.c.).

Los móviles o efectos económicos también intervienen a la hora de prever la observancia del Derecho por sus destinatarios o la eventualidad de que se infrinjan mandatos o prohibiciones. El legislador puede intuir que la valoración de la utilidad o las desventajas económicas de una regulación jurídica condiciona el propósito de cumplirla más decisiva y poderosamente que las motivaciones tradicionalmente invocadas para justificar el deber de sumisión al Derecho. Los destinatarios de las normas jurídicas hacen consideraciones simplemente económicas sobre los riesgos inherentes a su desobediencia. Si la conclusión les estimula, optan por desobedecerlas sin que otras preocupaciones -éticas o estéticas- prevalezcan sobre el resultado de ese juicio y les disuadan de una elección tan poco edificante.

\section{Respeto a las dimensiones de la libertad}

Todo sector del ordenamiento jurídico reacciona —más o menos enérgicamente- ante las exigencias del espíritu de transformación y de progreso.

La acogida de un sistema formal de derechos y libertades presuponía su asunción por cuantos estaban llamados a ser sus titulares, aunque la perfección de este objetivo no incumbía a los poderes públicos, de cuyo oficio no formaba parte la supresión de los obstáculos que demoraban su posibilidad ni la creación de las circunstancias que la favorecían. No había razones inmediatas para liquidar los desequilibrios reflejados en el dominio que los agentes decisivos de la vida social y económica ejercían sobre el resto de los pobladores que compartían una posición de dependencia. Los desposeídos — simples sujetos, sin función ni utilidad visibles, de aquellas facultades - carecían de estímulos y de oportunidades para adueñarse de los intereses anejos a su disfrute y ejercicio. Los do- 
minadores tenían a su alcance toda clase de medios para mantener y acrecentar los factores causantes del estado de opresión y de desigualdad que era la clave de su supremacía.

El afán de superar la situación no pasó, en un principio, de constituir un pío deseo de resultado inaccesible, pues, pese a la tenacidad de los empeños acumulados para conseguirlo, la adquisición de las añoradas igualdad y libertad materiales se redujo a un cambio de etiqueta que, por obra de conocidos entorpecimientos, logró dejar las cosas como estaban. De ahí que, a cambio de discretas innovaciones de lo accidental, no se diesen los esperados cambios sustanciales.

Estas insuficiencias y fracasos mostraron cómo la devaluación de las ideas de igualdad y libertad traicionaba los compromisos contraídos para recuperar, a toda costa, sus identidades. No se trataba de volver a los orígenes del mismo proyecto frustrado, sino de dar la definitiva batalla y — una vez ganada - afianzar la instalación victoriosa de aquéllas en los dominios que por derecho propio les pertenecían. La igualdad y la libertad debían ser, así las cosas, reales - en cuanto perceptibles y plasmadas en modelos de utilidad concreta - y adherirse irreversiblemente al acervo de bienes jurídicos de las personas y grupos sociales más necesitados de regeneración y crecimiento. Una y otra tenían que ser efectivas, no bastando la escueta eficacia o simple posibilidad de desencadenar las consecuencias previstas en la norma jurídica del caso, sino procurando que las mismas fuesen acompañadas de un ingrediente de justicia material.

Un Derecho objetivo sensible a tales exigencias cuida de rehabilitar -mediante acciones de saneamiento- las situaciones que de antiguo se debían al imperio de los poderes de hecho, a la pasividad de los legisladores y la ausencia de una clase de juristas comprometidos y rebeldes. Ciertos ordenamientos jurídicos adoptan una cláusula transformadora (arts. 3 II CI y 9.2 CE) que, con más o menos dosis de sinceridad e intensidad de propósito, transmite a los poderes públicos la consigna de velar celosamente por el rescate y la conservación de la igualdad y la libertad, emancipándolas, de una vez por todas, de las servidumbres y ataduras que las desnaturalizan y pervierten. Ello requiere poner fin a las discriminaciones y depresiones llamativas, y alienarse, sin tregua, en el esfuerzo de transformación. Objetivo a que se llega desigualando las situaciones cuya reconstrucción igualatoria encierra la clave del advenimiento a una sociedad verdadera y totalmente liberada.

Así se afronta un problema soluble con arreglo a los límites y la elasticidad del poder de decisión política de los legisladores. No han sido los ordenamientos jurídicos expresamente urgidos por una consigna de transformación los que han revelado mayor celo y sensibilidad a la hora de responder a sus requerimientos. 


\section{Judicialización y composición de conflictos}

Todo sector del ordenamiento jurídico se singulariza por el modo y medida en que sus normas se aplican por los órganos jurisdiccionales o se usa de otros mecanismos adecuados a la especificidad del Derecho objetivo o de la contienda que se entabla.

Quedó atrás la idea ingenua de que todas las normas jurídicas agotaban sus efectos pacificadores en las operaciones de los silogismos judiciales estereotipados y simplistas. No es tarea fácil la de enunciar y ordenar, con algún esmero y persuasión, la variedad de cauces útiles para que aquéllas adquieran la deseable efectividad y provoquen las transformaciones que augura su mensaje. El juego de su aplicación registra —además de estas objeciones de método- el dato cualitativo de la incidencia de las realidades sociales - del tiempo y del lugar- en el entendimiento de sus regulaciones y en las relecturas de que son susceptibles (art. 3.1 C.c.).

Cuando a las cláusulas tradicionales de garantía judicial (arts. 117.1 CE y 1.1 LOPJ) se suma el reconocimiento de un derecho a obtener la efectiva tutela de los jueces ordinarios (arts. $24.1 \mathrm{CE}$ y $11.3 \mathrm{LOPJ}$ ), no hay excusa ni trabas para privar de acceso a la jurisdicción a ninguna de las contiendas que surgen en los diversos sectores del ordenamiento jurídico. Cosa distinta es que las dificultades con que se tropieza, al construir un modelo adecuado de proceso, se manejen como pretexto para rehusar a la judicialización de los litigios el espacio omnicomprensivo que le corresponde. La resistencia a regular el tratamiento judicial de los conflictos económicos - peculiares de las relaciones colectivas de trabajo- acredita esa criticable inhibición.

Nada de esto implica la canonización de las soluciones judiciales y su elevación a modos óptimos de decisión de controversias. La efectiva tutela judicial es, sin más pretensiones, una especie del ensayo del esfuerzo de transformación y obedece al convencimiento de que los ámbitos de acceso a la jurisdicción acusan carencias llamativas y urgentemente remediables. Sin perjuicio de esta función liberadora, el examen y diagnóstico de cada sector del ordenamiento jurídico ilustran acerca de si la judicialización de los litigios, a que afectan sus normas, representa la solución recomendable o si es del caso acudir a otras vías de composición. Cauces que, en ocasiones, suplen lisa y llanamente la justicia mal administrada, en que consiste la justicia tardía, y que, otras veces, intervienen porque la acción de la justicia ordinaria no es la mejor para proveer a la satisfacción tempestiva del interés puesto en cuestión.

Ciertos prejuicios y desajustes culturales dificultan la naturalidad y flexibilidad de estas opciones progresivas. Con todos los recelos que se manifiestan en orden a la acción de los jueces ordinarios, la sociedad no 
ha conseguido superar la actitud de inestabilidad y desconfianza que, en comparación con la administración de justicia oficial, adopta frente a una novedad a la que habrá de acomodarse, persuadida, sin duda, de que la excelencia de sus ventajas supera con mucho lo temible de sus inconvenientes.

\section{Abreviaturas y Siglas}

art. artículo.

cap. capítulo.

C.c. $\quad$ Código Civil español de 24.7. (8) 89.

CE Constitución española de 27.12.78.

CI Constitución italiana de 27.12.47.

EMTPC.c. Exposición de Motivos de la L.31.5.74, de reforma del Título Preliminar del Código Civil.

ET Estatuto de los Trabajadores (Ley de 10.3.80).

LEC Ley de Enjuiciamiento Civil de 3.2. (8) 81.

LOPJ Ley Orgánica del Poder Judicial de 1.7.85.

LOTJ Ley Orgánica del Tribunal Constitucional de 3.10.79.

p. parágrafo.

tít. título.

TPC.c. Título Preliminar del Código Civil (L.31.5.74). 